\title{
ESTUDO DO PROCESSO DE EXTRAÇÃO POR SOXHLET DO ÓLEO DE SEMENTE DE UVA
}

\author{
M. L. de MENEZES ${ }^{1}$, J. MEDEIROS ${ }^{1}$, V. Y. KAJIHARA ${ }^{1}$, M. S. C. SAKAMOTO ${ }^{1}$, S. T. D de \\ BARROS $^{1}$ e N. C. PEREIRA ${ }^{1}$ \\ ${ }^{1}$ Universidade Estadual de Maringá, Departamento de Engenharia Química \\ E-mail para contato: maraisalm@ hotmail.com
}

\begin{abstract}
RESUMO - Este trabalho teve como objetivo a determinação das melhores condições de extração do óleo bruto de sementes de uva Cabernet Sauvignon e Bordô, utilizando-se como método o Soxhlet. Para tanto, as sementes foram previamente secas em secador convectivo de leito fixo nas temperaturas de $30,40,50,60,70$ e $80^{\circ} \mathrm{C}$ e velocidade do ar de $0,8 \mathrm{~m} / \mathrm{s}$. Os solventes utilizados foram o acetato de etila, hexano e o diclorometano e os tempos de extração estudados foram de 4, 8, 16, 24 e 48 horas. Na melhor condição de extração, o óleo foi caracterizado quanto à sua composição em ácidos graxos, massa específica, teor de umidade, índices de refração, acidez, peróxido, saponificação e iodo, matéria insaponificável, clorofila, fósforo total e reologia. Os resultados mostraram que o óleo de semente de uva apresentou um elevado teor de ácido linoleico, entre 636 e $665 \mathrm{mg} / \mathrm{g}$, e um comportamento de fluxo que acompanha o modelo Newtoniano.
\end{abstract}

\section{INTRODUÇÃO}

No Brasil, a vitivinicultura é uma prática consolidada, sendo que, em âmbito internacional, esta atividade brasileira ocupou em 2006, o $22^{\circ}$ lugar em área cultivada com uvas, o $16^{\circ}$ lugar em produção de uvas e o $15^{\circ}$ lugar em produção de vinhos (Oliveira, 2010). Além disso, com relação ao total de uvas produzidas no Brasil, de 50 a $60 \%$ são direcionadas para elaboração de vinhos, sucos e outros derivados, sendo que um grande problema gerado por esta intensa atividade é a quantidade de resíduos produzidos pelas agroindústrias, principalmente na elaboração de vinhos, uma vez que a cada 100 litros da produção, são gerados $31,7 \mathrm{~kg}$ de resíduos (Campos, 2005).

Atualmente, existe um interesse crescente na exploração dos resíduos gerados pela indústria do vinho, sendo que os principais subprodutos da vinificação são: o bagaço, constituído pelas sementes e cascas de uvas, o folhelho, o engaço, as borras e o sarro. Das cascas de uvas podem ser extraídas as antocianidinas, utilizadas como corantes na indústria alimentícia, enquanto que das sementes, pode ser extraído o óleo de semente de uva (Arvanitotannis et al., 2006).

Desde 1930 o óleo de semente de uva vem sendo utilizado como óleo comestível. A Alemanha, França e Itália foram os primeiros países a beneficiarem a semente de uva, enquanto que na América do Sul foram Argentina e Chile (Miguel, 1983). Atualmente, os maiores produtores mundiais de óleo de semente de uva são Estados Unidos, Espanha e Itália (Freitas, 2007). Este óleo é rico em tocoferol (vitamina E - antioxidante) principalmente sob a 
forma de alfa-tocoferol. Também possui grandes quantidades de ácidos graxos, destacando-se o elevado teor de ácido linoleico, que é essencial ao ser humano (Moretto e Fett, 1998).

Como um método convencional para a obtenção de óleo a partir de grãos e sementes, tem-se a extração com solvente (Soxhlet). O uso do solvente tem a vantagem de produzir um farelo com menos de $1 \%$ de óleo, independentemente do teor inicial do material, e, por isso, pode-se afirmar que este método de extração é mais eficiente que a prensagem, principalmente quando se utiliza grãos oleaginosos com um baixo teor de óleo (Oliveira, 2010).

A produção do óleo de semente de uva é uma alternativa de uso para um dos resíduos das vinícolas brasileiras, propondo uma utilização mais nobre das sementes e gerando um subproduto com qualidade equivalente ao óleo importado para utilização comercial. Desta maneira, o objetivo geral deste trabalho foi realizar a extração do óleo de semente de uva das variedades Cabernet Sauvignon e Bordô por Soxhlet, bem como a determinação da melhor condição de extração, identificação e quantificação dos compostos orgânicos e caracterização físico-química do óleo.

\section{METODOLOGIA}

\subsection{Preparação da Matéria-Prima}

As sementes de uva da variedade Bordô foram fornecidas pela Vinícola Vinhos Randon Ltda. (Pinheiro Preto - SC), enquanto as sementes da variedade Cabernet Sauvignon foram fornecidas pela Vinícola Toledo (Toledo - PR). Elas foram limpas para a remoção dos demais resíduos do processamento das uvas que estavam junto com as sementes. Para isso, colocaram-se as sementes em peneiras, lavando-as com água corrente para a retirada das cascas, engaço e açúcar. Em seguida, foram lavadas novamente com água deionizada e, posteriormente, com água deionizada aquecida a $100^{\circ} \mathrm{C}$. As sementes limpas foram secas à temperatura ambiente, embaladas em sacos plásticos e guardadas sob refrigeração $\left(-15^{\circ} \mathrm{C}\right)$.

\subsection{Processo de Extração}

Para o processo de extração, as sementes limpas foram previamente secas em secador convectivo de leito fixo nas temperaturas de $30,40,50,60,70$ e $80{ }^{\circ} \mathrm{C}$ e velocidade de ar de $0,8 \mathrm{~m} / \mathrm{s}$. Antes de cada extração, as sementes foram trituradas em um triturador modelo TE345 por 10 segundos, homogeneizadas, e trituradas por mais 10 segundos. Para as extrações com Soxhlet foram utilizados solventes hexano, diclorometano e o acetato de etila, sendo as extrações realizadas na temperatura de ebulição do solvente. As extrações foram feitas em duplicatas com, aproximadamente, 10 gramas de sementes já trituradas, e $300 \mathrm{~mL}$ de solvente. Os tempos de extração foram de 4, 8, 16, 24 e 48 horas.

Após o período de extração, a amostra, contendo o óleo e o solvente, foi recolhida no balão. Para a recuperação do solvente, a amostra foi levada a um evaporador rotativo Fisatom 802. O cálculo do teor de óleo extraído por Soxhlet foi realizado conforme a Equação 1.

$$
\% \text { Teor de óleo }=\frac{m_{\text {olleo }}}{m_{\text {semente }}} 100
$$


em que: $m_{\text {óleo }}$ é a massa de óleo extraída, em gramas, e $m_{\text {semente }}$ é a massa de semente de uva, em gramas, utilizada em cada extração.

\subsection{Análise Estatística da Extração}

Foi realizada uma análise de variância para verificar se houve diferença significativa entre os tratamentos, ao nível de 5\% de probabilidade, com relação ao teor de óleo obtido, utilizando-se o software Statistica $7.1^{\circledR}$. A análise da melhor condição do processo de extração foi realizada por meio da Metodologia de Superfície de Resposta.

\subsection{Caracterização do Óleo de Semente de Uva}

A identificação e quantificação de compostos orgânicos presentes no óleo de semente de uva foram realizadas utilizando-se a cromatografia em fase gasosa. Além da cromatografia, foram realizadas as seguintes análises de acordo com a metodologia oficial do Instituto Adolfo Lutz (1985): índice de acidez, índice de saponificação, matéria insaponificável, índice de iodo e índice de refração, bem como massa específica, viscosidade e teor de umidade.

\section{RESULTADOS E DISCUSSÃO}

\subsection{Análise Estatística da Extração}

A partir dos valores de teor de óleo calculados, foram feitas curvas de superfície de resposta para cada solvente analisado, sendo as curvas para as variedades Cabernet Sauvignon e Bordô extraídas com diclorometano estão apresentadas na Figura 1.
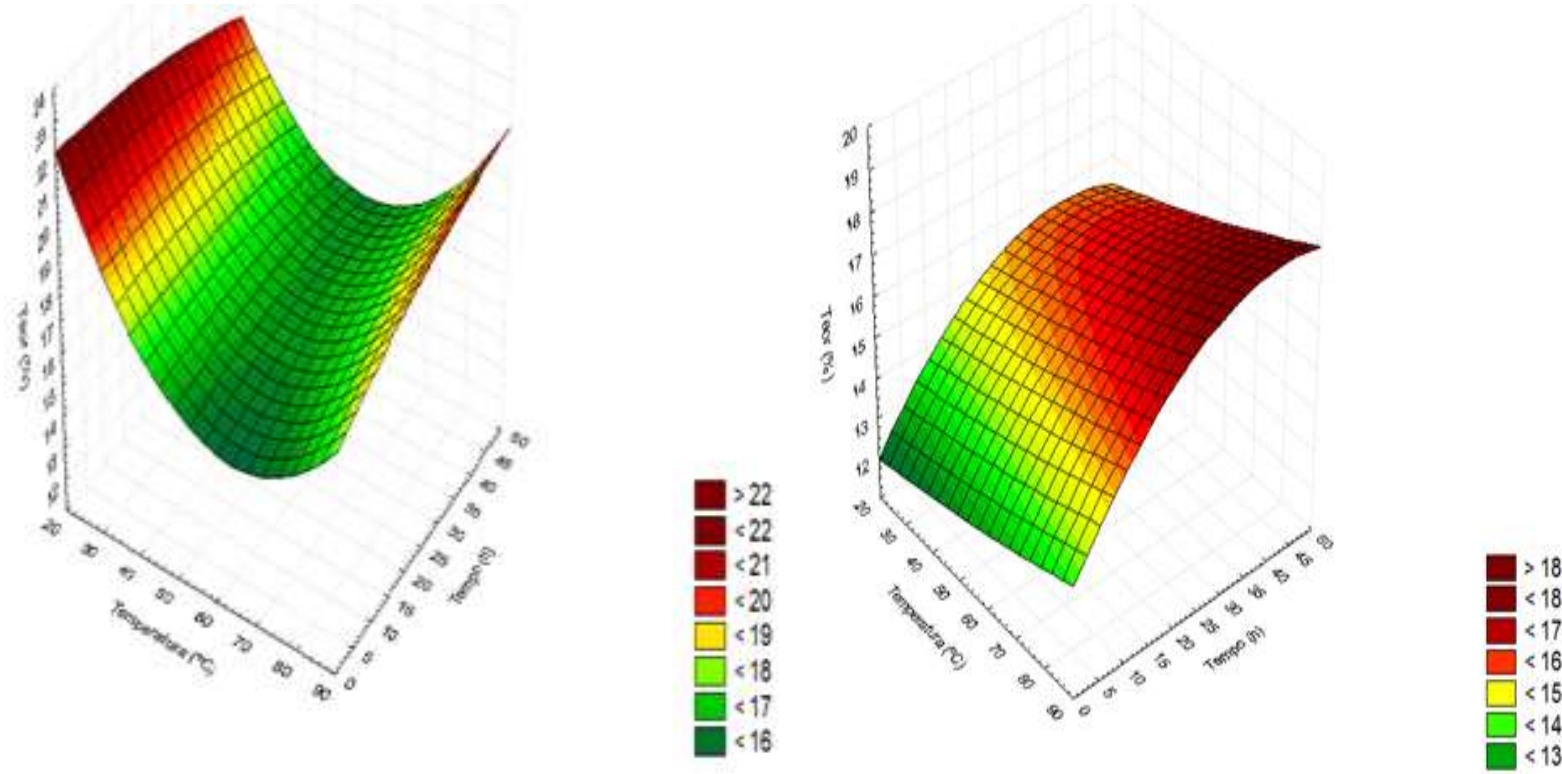

Figura 1 - Superfície de resposta obtida utilizando sementes de uva Cabernet Sauvignon (à esquerda) e Bordô (à direita) e diclorometano como solvente.

Entre o acetato de etila, o hexano e o diclorometano, o último foi o que apresentou mai- 
or teor de óleo. Por meio da Figura 1, é possível verificar que a melhor condição de extração por Soxhlet do óleo de sementes de uva Cabernet Sauvignon e Bordô, com base no maior teor de óleo, foi obtida utilizando sementes secas em elevadas temperaturas $\left(80^{\circ} \mathrm{C}\right)$. O teor de óleo obtido no tempo de extração de 48 horas não diferiu significativamente do obtido em 16 horas de extração, sendo este último, portanto, o melhor tempo de extração para ambas as sementes. $\mathrm{Na}$ melhor condição de extração, os teores de óleo obtidos foram de 20 e $16,5 \%$ para as sementes de uva Cabernet Sauvignon e Bordô, respectivamente.

A partir do planejamento fatorial completo, foram obtidas as variáveis significativas na extração de óleo de semente de uva Cabernet Sauvignon e Bordô para cada solvente analisado. As Tabelas 1 e 2 apresentam a análise de variância para os fatores e para a interação utilizando como solvente o diclorometano.

Tabela 1 - Tabela ANOVA para as extrações da variedade Cabernet Sauvignon com diclorometano

\begin{tabular}{|c|c|c|c|c|c|}
\hline Fonte de variação & $\begin{array}{c}\text { Graus de } \\
\text { Liberdade }\end{array}$ & $\begin{array}{c}\text { Soma dos } \\
\text { Quadrados }\end{array}$ & $\begin{array}{c}\text { Soma dos } \\
\text { Quadrados Médios }\end{array}$ & f & p-valor \\
\hline Temperatura & 1 & 54,1306 & 54,1306 & 14,4805 & 0,0004 \\
\hline Temperatura $^{2}$ & 1 & 41,6763 & 41,6763 & 11,1488 & 0,0015 \\
\hline Tempo & 1 & 0,7374 & 0,7374 & 0,1972 & 0,6587 \\
\hline Tempo $^{2}$ & 1 & 1,0619 & 1,0619 & 0,2841 & 0,5962 \\
\hline Temperatura*Tempo & 1 & 8,6521 & 8,6521 & 2,3145 & 0,1340 \\
\hline Erro & 54 & 201,8614 & 3,7382 & & \\
\hline
\end{tabular}

Tabela 2 - Tabela ANOVA para as extrações da variedade Bordô com diclorometano

\begin{tabular}{|c|c|c|c|c|c|}
\hline Fonte de variação & $\begin{array}{c}\text { Graus de } \\
\text { Liberdade }\end{array}$ & $\begin{array}{c}\text { Soma dos } \\
\text { Quadrados }\end{array}$ & $\begin{array}{c}\text { Soma dos } \\
\text { Quadrados Médios }\end{array}$ & f & p-valor \\
\hline Temperatura & 1 & 0,0490 & 0,0490 & 0,02592 & 0,872800 \\
\hline Temperatura $^{2}$ & 1 & 0,0441 & 0,0441 & 0,02331 & 0,879219 \\
\hline Tempo & 1 & 16,6686 & 16,6686 & 8,81662 & 0,004445 \\
\hline Tempo $^{2}$ & 1 & 13,8383 & 13,8383 & 7,31958 & 0,009107 \\
\hline Temperatura*Tempo & 1 & 0,2676 & 0,2676 & 0,14157 & 0,708200 \\
\hline Erro & 54 & 102,0917 & 1,89059 & & \\
\hline
\end{tabular}

A partir da Tabela 1, verifica-se que apenas a temperatura apresentou p-valor menor que $5 \%$ e, portanto, é uma variável significativa no processo de extração para a variedade Cabernet Sauvignon, diferente do que ocorreu para a variedade Bordô, em que o tempo é variável significativa.

\subsection{Análise Físico-Química do Óleo}

A Tabela 3 mostra a composição de ácidos graxos do óleo de semente de uva bruto, bem como os valores de referência da ANVISA (1999) para óleo refinado. 
Tabela 3 - Composição de ácidos graxos

\begin{tabular}{|c|c|c|c|c|c|}
\hline \multirow{2}{*}{$\begin{array}{c}\text { Ácido graxo } \\
\text { (em mg/g de óleo) }\end{array}$} & \multicolumn{2}{|c|}{$40^{\circ} \mathrm{C}$} & \multicolumn{2}{|c|}{$80^{\circ} \mathrm{C}$} & \multirow{2}{*}{ ANVISA } \\
\hline Mirístico & $0,83 \pm 0,03$ & $0,83 \pm 0,01$ & $0,74 \pm 0,01$ & $0,60 \pm 0,04$ & $<3$ \\
\hline Palmítico & $79,98 \pm 0,36$ & $68,37 \pm 2,10$ & $80,24 \pm 0,80$ & $65,16 \pm 0,45$ & $55-110$ \\
\hline Esteárico & $37,88 \pm 0,23$ & $32,22 \pm 0,21$ & $38,62 \pm 0,06$ & $30,88 \pm 0,34$ & $30-60$ \\
\hline Oleico & $139,78 \pm 0,64$ & $176,81 \pm 1,25$ & $138,30 \pm 0,41$ & $164,46 \pm 0,39$ & $120-$ \\
\hline Linoleico & $668,13 \pm 1,85$ & $652,55 \pm 9,42$ & $665,67 \pm 3,06$ & $636,51 \pm 2,46$ & $580-780$ \\
\hline Linolênico & $4,37 \pm 0,08$ & $4,86 \pm 0,11$ & $4,10 \pm 0,05$ & $4,11 \pm 0,01$ & $<10$ \\
\hline Araquídico & $1,78 \pm 0,03$ & $1,63 \pm 0,04$ & $1,72 \pm 0,02$ & $1,49 \pm 0,03$ & $<10$ \\
\hline Behênico & $0,47 \pm 0,01$ & $0,31 \pm 0,00$ & $0,47 \pm 0,01$ & $0,35 \pm 0,00$ & $<3$ \\
\hline
\end{tabular}

Os resultados obtidos mostram que o óleo das sementes de ambas as variedades apresentam composições similares, sendo que os ácidos graxos encontrados em maior quantidade foram o linoleico, o oleico, o palmítico e o esteárico. Além disso, verifica-se que a composição de ácidos graxos das duas variedades de uva apresentam-se dentro das especificações da ANVISA (1999), mesmo que o óleo analisado não tenha sido refinado.

A Tabela 4 mostra os resultados das análises físico-químicas para o óleo de semente de uva bruto e os valores de referência da ANVISA (1999) para óleo refinado.

Tabela 4 - Análises físico-químicas para o óleo de semente de uva

\begin{tabular}{|c|c|c|c|c|c|}
\hline \multirow{2}{*}{ Análises } & \multicolumn{2}{|c|}{$40^{\circ} \mathrm{C}$} & \multicolumn{2}{|c|}{$80^{\circ} \mathrm{C}$} & \multirow{2}{*}{ ANVISA } \\
\hline & Cabernet & Bordô & Cabernet & Bordô & \\
\hline $\begin{array}{c}\text { Massa específica } \\
\left(20^{\circ} \mathrm{C}\right)\end{array}$ & $0,95 \pm 0,02$ & $0,94 \pm 0,01$ & $0,93 \pm 0,01$ & $0,94 \pm 0,01$ & $\begin{array}{c}0,923- \\
0,926\end{array}$ \\
\hline $\begin{array}{l}\text { Índice de refração } \\
\qquad\left(\mathrm{n}_{\mathrm{D}}{ }^{40}\right)\end{array}$ & $1,47 \pm 0,01$ & $1,47 \pm 0,02$ & $1,47 \pm 0,01$ & $1,47 \pm 0,01$ & $\begin{array}{c}1,473- \\
1,477\end{array}$ \\
\hline $\begin{array}{l}\text { Índice de saponificação } \\
(\mathrm{mg} \mathrm{KOH} / \mathrm{g})\end{array}$ & $190,84 \pm 0,68$ & $188,28 \pm 0,64$ & $190,60 \pm 0,22$ & $188,81 \pm 0,21$ & $\begin{array}{c}188- \\
194\end{array}$ \\
\hline $\begin{array}{l}\text { Índice de iodo } \\
\text { (Wijs) }\end{array}$ & $134,44 \pm 0,43$ & $132,71 \pm 0,61$ & $135,09 \pm 0,30$ & $132,44 \pm 0,34$ & $\begin{array}{c}130- \\
138\end{array}$ \\
\hline $\begin{array}{l}\text { Matéria insaponificável } \\
(\%)\end{array}$ & $2,00 \pm 0,03$ & $1,50 \pm 0,02$ & $1,50 \pm 0,03$ & $1,50 \pm 0,02$ & $\begin{array}{l}\text { Máximo } \\
2,0\end{array}$ \\
\hline $\begin{array}{l}\text { Índice de acidez } \\
\text { (mg KOH/g) }\end{array}$ & $2,09 \pm 0,05$ & $1,87 \pm 0,07$ & $2,10 \pm 0,06$ & $1,60 \pm 0,02$ & $\begin{array}{l}\text { Máximo } \\
0,3\end{array}$ \\
\hline $\begin{array}{l}\text { Teor de umidade } \\
(\%)\end{array}$ & $0,30 \pm 0,01$ & $0,34 \pm 0,01$ & $0,26 \pm 0,01$ & $0,22 \pm 0,01$ & - \\
\hline
\end{tabular}

A partir dos dados da Tabela 4, verifica-se que os valores de massa específica, índice de refração e índice de acidez não se encontram dentro dos padrões da ANVISA (1999) para óleo 
refinado. Sendo o índice de acidez um parâmetro utilizado para a avaliação do nível de degradação do óleo, pode-se afirmar que o óleo deverá passar por algum tipo de tratamento antes de sua comercialização.

Segundo Moretto e Fett (1998), quanto maior o índice de saponificação, melhor o óleo para a alimentação. A Tabela 4 indica valores de índice de saponificação para as diferentes condições de extração dentro dos valores especificados pela ANVISA (1999), sendo os valores aproximadamente iguais levando em consideração apenas a temperatura de secagem como fator de variação. Além disso, o óleo das sementes da variedade Cabernet Sauvignon com valores de índice de saponificação ligeiramente maiores que os da variedade Bordô, indicando que a primeira é melhor em termos alimentares.

O índice de iodo está relacionado ao grau de insaturação (Instituto Adolfo Lutz, 1985). Quanto maior a quantidade de insaturações, maior a capacidade de absorção do iodo pelo óleo. Pela Tabela 4, verifica-se que os valores de índice de iodo apresentados para a variedade Cabernet Sauvignon e, por consequência o grau de insaturação, são maiores que os valores apresentados para a variedade Bordô, podendo ser explicado pela maior quantidade de ácido linoleico (18:2n-6) presente na primeira variedade $\left(668,13\right.$ e $665,67 \mathrm{mg} / \mathrm{g}$ para 40 e $80{ }^{\circ} \mathrm{C}$, respectivamente) em comparação com a segunda $\left(652,55\right.$ e $636,51 \mathrm{mg} / \mathrm{g}$ para 40 e $80^{\circ} \mathrm{C}$, respectivamente). Cabe verificar, ainda, que os valores de índice de iodo de ambas as variedades encontram-se dentro dos valores padrão para o óleo refinado.

Os valores de matéria insaponificável para os óleos analisados são menores ou iguais ao limite estabelecido. Chinazzo (2010) determinou um valor de 0,5\% para matéria insaponificável para o óleo de sementes de uva Isabel, sendo que a diferença entre os resultados deste trabalho e do autor consiste no fato de que Chinazzo (2010) obteve o óleo a partir de sementes in natura.

Embora não tenha valor de comparação pelas especificações da ANVISA (1999), o teor de umidade é um parâmetro importante na prevenção da deterioração do óleo, visto que a umidade em contato com o oxigênio do ar promove a rancidez oxidativa. Além disso, a umidade também é um dos fatores que favorece a proliferação de micro-organismos que aceleram a decomposição do produto.

A Figura 2 mostra o comportamento da viscosidade do óleo em função da temperatura.
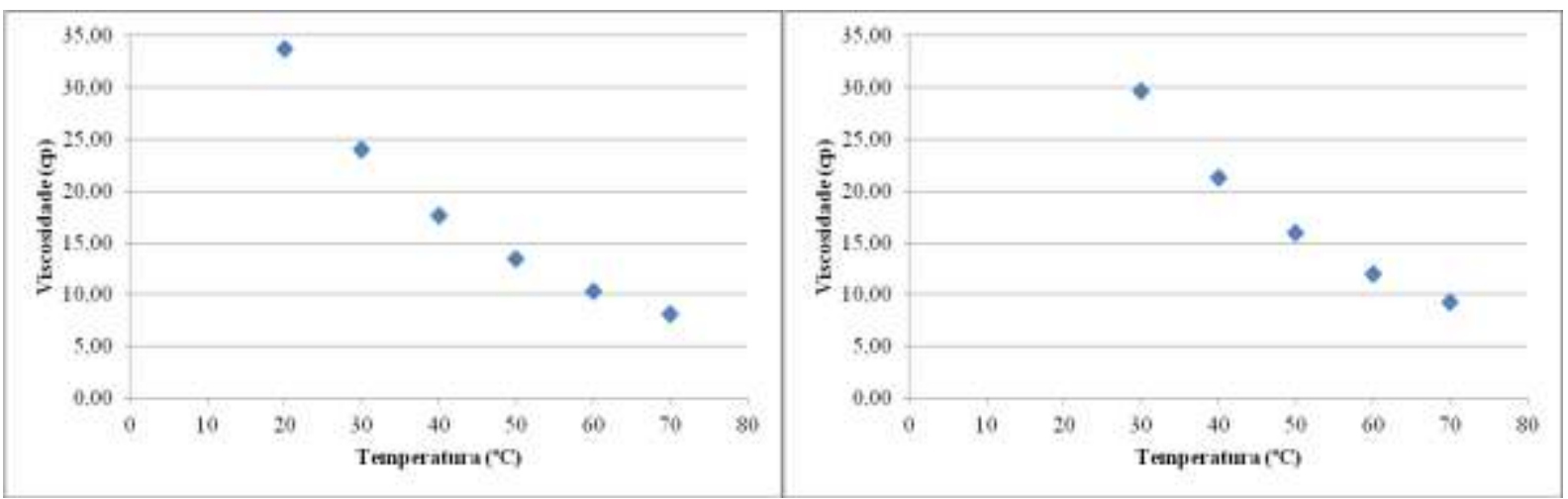

Figura 2 - Variação de viscosidade do óleo com a temperatura - variedade Cabernet 
Sauvignon seca à $40^{\circ} \mathrm{C}$ (à esquerda) e $80^{\circ} \mathrm{C}$ (à direita).

A partir da Figura 2, observa-se que a viscosidade do óleo da variedade Cabernet Sauvignon é decrescente em relação ao aumento da temperatura, comportamento esperado para todo líquido, e que, quanto maior a temperatura, menor esta variação, sendo o mesmo comportamento verificado para a variedade Bordô. Entretanto, obteve-se que o óleo da primeira variedade tem a viscosidade maior que a da segunda, sendo que a $20^{\circ} \mathrm{C}$, obtiveram-se valores de viscosidade de 33,70 e 42,90 cP para a Cabernet Sauvignon seca às temperaturas de 40 e $80^{\circ} \mathrm{C}$, respectivamente, e, para a Bordô, 17,50 e 26,00 cP para a menor e maior temperaturas de secagem, respectivamente.

A Figura 3 mostra os gráficos de tensão de cisalhamento por taxa de cisalhamento.
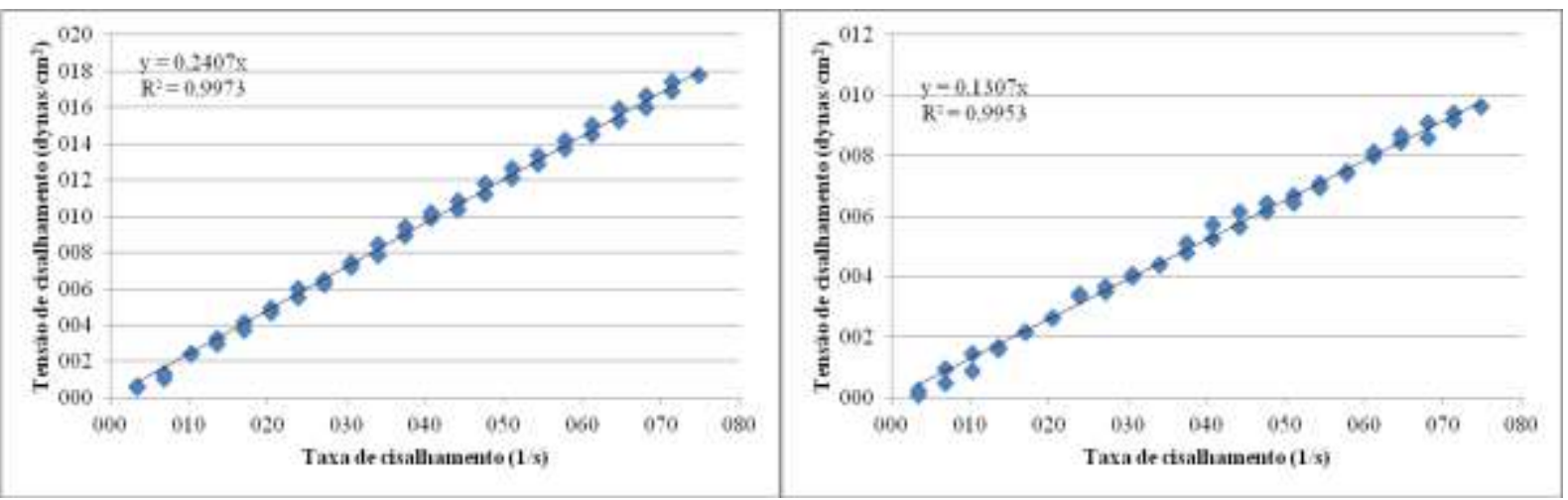

Figura 3 - Gráfico de tensão de cisalhamento versus taxa de cisalhamento a $30^{\circ} \mathrm{C}$ - variedades Cabernet Sauvgnon (à esquerda) e Bordô (à direita) secas à $40^{\circ} \mathrm{C}$.

A Figura 3 mostra que a equação de reta tem bom ajuste para os dados experimentais, com valores de $\mathrm{R}^{2}$ muito próximos de 1 . Além disso, nenhuma das equações das retas ajustadas tem coeficiente linear diferente de zero, o que classifica o óleo de semente de uva como fluido newtoniano, sendo o mesmo resultado obtido para as sementes secas à $80^{\circ} \mathrm{C}$.

\section{CONCLUSÃO}

A partir da análise estatística dos valores de teor de óleo obtidos, obtiveram-se que as melhores condições de extração foram de temperaturas altas, tempo de extração de 16 horas e utilizando o diclorometano como solvente para ambas as variedades. Além disso, por meio da análise de variância, verificou-se que apenas a temperatura é variável significativa no processo de extração para a variedade Cabernet Sauvignon, bem como o tempo de extração para a variedade Bordô.

A cromatografia em fase gasosa mostrou a presença de vários ácidos graxos no óleo de semente de uva benéficos para a saúde, tendo sido constatadas principalmente altas quantidades de ácido linoleico e ácido oleico. Ademais, os valores de índice de saponificação, índice de iodo e matéria insaponificável encontraram-se dentro das especificações da ANVISA (1999) para óleo refinado. Entretanto, os valores de massa específica, índice de refração e índice de acidez não concordaram com tais normas, sendo importante ressaltar que o óleo analisado não passou por algum processo de purificação. Assim, segundo as características físico- 
químicas, o óleo de semente de uva obtido por Soxhlet apresentou grande potencial de produção nacional.

\section{REFERÊNCIAS BIBLIOGRÁFICAS}

ANVISA. Resolução $\mathrm{n}^{\circ}$ 482, de 23 de setembro de 1999. Regulamento técnico para fixação de identidade e qualidade de óleos e gorduras vegetais. Diário Oficial da República Federativa do Brasil, Brasília, 1999.

ARVANITOYANNIS, I. S.; LADAS, D.; MAVROMATIS, A. Potential uses and applications of treated wine waste: a review. Int. J. of Food Sci. Technol., v. 41, p. 475-487, 2006.

CAMPOS, L. M. A. S.; MICHIELIN, E. M. Z.; DANIELSKI, L.; FERREIRA, S. R. S., Experimental data and modeling the supercritical fluid extraction of marigold (Calendulaof.cinalis) oleoresin. J. Supercritical Fluids, v.34, n.2, p.163-170, 2005.

CHINAZZO, I. R. Influência da cultivar e do tipo de agricultura na concentração de compostos antioxidantes em óleos de semente de uva. 2010. Trabalho de conclusão de curso (Engenharia de Alimentos),Universidade Federal do Rio Grande do Sul, Porto Alegre, 2010.

FREITAS, L. S. Desenvolvimento de procedimentos de extração do óleo de semente de uva e caracterização química dos compostos extraídos. 2007. Tese (Doutorado em Química), Universidade Federal do Rio Grande do Sul, Porto Alegre, 2007.

INSTITUTO ADOLFO LUTZ, Normas Analíticas. Métodos Químicos e Físicos para Análise de Alimentos, v.1, $3^{\text {a }}$ ed., São Paulo, 1985.

MIGUEL, L. Formulações com óleo de sementes de uva "Suvalan”. Porto Alegre: Faculdade de Farmácia da UFRS, 1983.

MORETTO, E.; FETT, R. Tecnologia de Óleos e Gorduras Vegetais na Indústria de Alimentos, Ed. Varela, São Paulo, 1998.

OLIVEIRA, D. A. Caracterização fitoquímica e biológica de extratos obtidos de bagaço de uva (Vítis Vinífera) das variedades Merlot e Syrah. 2010. Dissertação (Mestrado em Engenharia de Alimentos), Universidade Federal de Santa Catarina, 2010.

VISENTAINER, J. V.; FRANCO, M. R. B. Ácidos Graxos em Óleos e Gorduras: Identificação e Quantificação, Ed. Varela, São Paulo, 2006. 